\title{
Bullying Victimization in Primary School: A Cross-Sectional Study in One Municipality in Belgrade
}

\author{
Darija Kisić-Tepavčevićn ${ }^{1}$, Tatjana Gazibara ${ }^{1}$, Milica Štrbački ${ }^{1}$, Vesna Kisićn ${ }^{2}$, Tatjana Pekmezović ${ }^{1}$ \\ ${ }^{1}$ Institute of Epidemiology, Faculty of Medicine, University of Belgrade, Belgrade, Serbia, ${ }^{2}$ Community Health Center \\ "Voždovac", Belgrade, Serbia
}

Correspondence: pekmezovic@sezampro.rs; Tel./Fax.: + 381113607062

Received: December 20, 2020; Accepted: February 18, 2020

\begin{abstract}
Objective - The objective of this study was to evaluate the prevalence and patterns of bullying victimization among primary school pupils. Our goal was also to structure evidence-based recommendations as to the main issues surrounding bullying victimization. Methods - A cross-sectional study included 380 primary school pupils from 6 primary schools located in the municipality of Voždovac, in the capital city of Belgrade, Serbia. Data were collected using an anonymous questionnaire. The questionnaire explored socio-demographic data, types, location and frequency of bullying as well as pupils' reactions to bullying. Results - One hundred fifty one pupils (39.7\%) reported being victims to bullying. The prevalence of bullying varied across school grades, but showed a decreasing tendency with more advanced grade at school $\left(58.3 \%\right.$ in $3^{\text {rd }}$ grade, $37.1 \%$ in $5^{\text {th }}$ grade and $26.3 \%$ in $7^{\text {th }}$ grade). Making jokes and exclusion from the group were the most frequent types of bullying. The most common location of bullying was inside the classroom (81.4\%) and school yard (61.8\%). Boys were more frequently victims of bullying compared with girls $\left(\chi^{2}\right.$ test $\left.=6.264 ; \mathrm{P}=0.012\right)$. Being younger correlated with more frequent reporting of bullying ( $\left.r h o=0.236 ; \mathrm{P}=0.001\right)$. Conclusion - Our findings call for bullying prevention programs in primary schools with the aim at improving teachers' competence to promptly recognize and respond to bullying. Bullying prevention programs should be compulsory for the teaching staff as well as for the pupils and their parents.
\end{abstract}

Key Words: Bullying • Victimization - Pupils • Primary School.

\section{Introduction}

At a global level, school bullying is a serious problem among children and adolescents (1). The importance of bullying for school health and for public health in general is related to the consequences of bullying that could have detrimental effect on physical (2), mental (3) and social (4) health and well-being. School bullying has been recognized as a complex phenomenon that requires systematic and multidisciplinary approach to resolution and prevention (5).

Bullying is a specific form of repeated aggression in which one or more persons intimidate and harass another person (6). Repeated aggression is one of the characteristics that differs bullying from single episodes of aggression. In addition, the imbalance of power between the perpetrators and the victims represents another key feature of bullying. This imbalance of power may be physical or psychological, but also accounts for name-calling, use of threats, spreading rumors or exclusion of a person from the peer group (7).

Victims of bullying tend to avoid going to school, exhibit higher levels of anxiety and lower self-esteem, have troubles concentrating and sleeping and have lower academic achievements compared to children who are not involved in bullying (8-10). Magnetic Resonance Imaging (MRI) showed that children aged 10 years who had fre- 
quently been bullied have specific morphological changes in the cerebral cortex compared to children who had never been bullied (11). Long-term consequences of bullying include posttraumatic stress disorder (12), poorer mental and physical health, which affect various aspects of life, such as relationships, work and economic independence (13). Compelling data from 48 countries worldwide showed that adolescents who experienced bullying were more likely to attempt suicide (14).

Evidence suggests that school bullying may start as early as the beginning of primary school (15). Certain children are more prone to being victims of bullying, such as those who are of different ethnicity compared to the majority of children at school, or those who are overweight or obese $(16,17)$. Victims of bullying more likely have chronic diseases (18), are less affluent or live in households with only one parent (19). Also, it has been observed that boys more often tend to be the perpetrators, while girls have more often been the victims of bullying (20). Bullying victimization often remains underreported to school teachers or parents, as victims feel ashamed or fear retaliation (21). Because of all aforementioned, research on bullying is important and has healthrelated, social and economic implications.

The purpose of this study was to evaluate the prevalence of bullying among primary school children and to describe the patterns of bullying victimization in a sample of children in primary schools in one municipality in the city of Belgrade.

\section{Methods}

\section{Setting and Participants}

A cross-sectional study was conducted in Belgrade, the capital city of the Republic of Serbia, during February 2008. Belgrade has a population of approximately 1.6 million people and 17 municipalities (22). Of those, 10 make the inner city of Belgrade. We randomly selected one municipality, Voždovac, for recruitment of the study participants. The municipality of Voždovac lies between the inner city and suburban metropolitan area. According to last Census, the municipality had 158,213 inhab- itants (23). Of those, 6,790 were children aged 5-9 years and 6,641 were children aged 10-14 years (23).

Of 23 primary schools located in the territory of Voždovac (24) we randomly selected 8 primary schools for the recruitment of study participants. Random selection of schools was conducted in the following manner: first, all 23 schools were listed alphabetically; second, names of schools were written on separate slips of paper which were folded two times and placed in a non-transparent bag; third, a person who did not participate in the previously described procedure chose 8 slips of paper from the bag, which corresponded to approximately one third of all schools in the municipality. In this way, we contacted 8 selected schools, however, 2 declined participation. In total, 6 primary schools were selected for the recruitment of study participants.

Primary schooling in Serbia is organized according to 8 grades/years. Children who turn 7 years of age are eligible to enter the first grade, although, occasionally children aged 6 years may start primary schooling (provided that the school psychologist grants that the child may be enrolled). Usually, children complete primary school by the age of 15 . In each school, we randomly selected one class in $3^{\text {rd }}, 5^{\text {th }}$ and $7^{\text {th }}$ grade, to account for various levels of primary schooling. One class has, at a minimum, 15 pupils, however, it is customary that there are 20-25 pupils per one class.

The sample size was calculated using Raosoft sample size calculator (25) based on margin of error of $5 \%$, confidence interval of $95 \%$, approximation of the population size of children aged 5-14 years residing in Voždovac (approximately 13,000) (23) and response distribution of $50 \%$. The calculated sample size was 374 children.

Of 398 pupils who were offered to fill in the anonymous questionnaire, 380 returned the questionnaires (response rate 95.5\%). This sample represents $2.9 \%$ of children aged $5-14$ years in the municipality of Voždovac reported in the 2011 Census (23). Because pupils were younger than 18 years, the schools in which we conducted the survey informed the parents in an opt-out manner. This means that the parents were informed about the survey and were asked to notify the school in case they did not want their children to take part in it. 


\section{Instrument}

Research data were collected using an anonymous questionnaire. The pupils filled in the questionnaire independently before the start of teaching classes. The questionnaire was constructed based on previous research on primary school bullying (26-28). The face validity of the questionnaire was verified on a pilot study sample of 15 primary school pupils aged $9-15$ years.

The questionnaire explored demographic characteristics of the participants, such as gender, age, parental education level, grade point average and number of siblings. The following part of the questionnaire explored bullying experience: general awareness as to the occurrence of bullying at their school, attitudes towards bullying and behaviors regarding a situation where one witnesses bullying of others. Answers related to bullying were graded on a 5-point Likert scale, where grade 1 referred to "I strongly disagree" and grade 5 referred to "I strongly agree". The last part of the questionnaire examined personal experiences of pupils relative to bullying: whether the pupils had been victims of bullying, who they asked for help, specific location of bullying and frequency of bullying.

\section{Ethical Considerations}

Ethical approval was obtained from the Institutional Review Board of the Institute of Epidemiology, Faculty of Medicine, University of Belgrade. The pupils provided consent for participation in the study.

\section{Statistical Analyses}

To describe the study sample, we applied methods of descriptive statistics (percentages, mean and standard deviation). Of analytical statistics, the Chi square test was used to examine differences between the categorical variables. The Spearman's correlation coefficient (rho) was used to evaluate correlation between the selected variables. The probability level of $\mathrm{P}<0.05$ was considered statistically significant. Data were analyzed using the Statistical Package for Social Sciences (SPSS, Inc, Chicago, IL, USA), version 15.0.

\section{Results}

Of 380 pupils, 199 (52.4\%) were boys and 181 $(47.6 \%)$ were girls. The average age of pupils was $11.2 \pm 1.7$ years. The youngest participant was 8 years old and the oldest was 14 years old. There were 115 pupils $(30.3 \%)$ in the $3^{\text {rd }}$ grade, $132(34.7 \%)$ in the $5^{\text {th }}$ and $133(35.0 \%)$ in the $7^{\text {th }}$ grade. The average age of the parents was $39.3 \pm 5.3$ years for mothers and $42.3 \pm 5.6$ for fathers.

Sixty point eight percent of pupils confirmed that in their schools certain pupils laugh, insult and call names of other pupils. Approximately $70 \%$ of pupils either strongly agreed or agreed that pupils joke about physical appearance and origin of their schoolmates. Thirty seven point nine percent of children strongly agreed and $22.1 \%$ agreed that fights occurred in their schools. Also, $8.2 \%$ pupils reported having heard of thefts (of either money, clothes and/or jewelry).

A total of $39.7 \%$ (151) of school children were victims of bullying. The prevalence of bullying varied across the school grades, but had a decreasing tendency with advancing grade at school $(58.3 \%$ in $3^{\text {rd }}$ grade, $37.1 \%$ in $5^{\text {th }}$ and $26.3 \%$ in $7^{\text {th }}$ grade). The types of bullying reported by the pupils are presented in Table 1. Making jokes and exclusion from the group were the most frequent types of bullying in our sample of primary school pupils. Slightly more than one half $(58.3 \%)$ confirmed that the perpetrators were their classmates. Additionally, boys were more frequently victims of bullying than girls $\left(\chi^{2}\right.$ test $=6.264 ; \mathrm{P}=0.012$ ).

A statistically significant correlation ( $\mathrm{rho}=0.236$; $\mathrm{P}=0.001)$ was observed between being younger and reporting bullying to adults. By contrast, older children had more frequently a tendency to avoid interfering because they did not care $\left(\chi^{2}=8.741 ; \mathrm{P}=0.013\right)$. It was observed that girls trusted more their principal teachers than boys $\left(\chi^{2}=8.741 ; \mathrm{P}=0.013\right)$, while boys did not react to bullying because "it was not their business" $\left(\chi^{2}=12.072 ; \mathrm{P}=0.001\right)$. The distribution of locations where episodes of bullying occurred were presented in Table 2. The pupils most commonly reported that bullying took place in the classroom or in the school yard. 


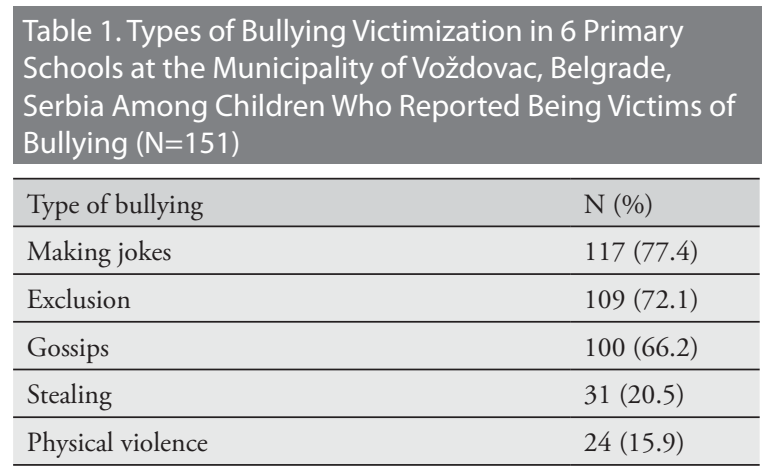

Table 2. Location of Bullying Victimization in 6 Primary Schools at the Municipality of Voždovac, Belgrade,

Serbia Among Children Who Reported Being Victims of Bullying $(\mathrm{N}=151)$

\begin{tabular}{ll}
\hline Location of bullying & $\mathrm{N}(\%)$ \\
\hline Classroom & $123(81.4)$ \\
\hline School yard & $94(62.9)$ \\
\hline On the way to/from school & $32(21.2)$ \\
\hline School corridors & $25(16.5)$ \\
\hline In school toilets & $16(10.6)$ \\
\hline In school sports hall & $7(4.6)$ \\
\hline In school sports field & $4(2.6)$ \\
\hline Other & $5(3.3)$ \\
\hline
\end{tabular}

The majority of bullying episodes (61.6\%) were reported to the class teacher. However, $27.6 \% \mathrm{pu}-$ pils revealed that they did not report bullying to their teachers because they were afraid. Only 3.7\% of pupils stated that the perpetrators were not punished. In terms of frequency of bullying, 54\% of children reported that bullying occurred yearly, while $4 \%$ of children reported that they experienced bullying every day.

\section{Discussion}

This study found that the prevalence of bullying victimization among primary school pupils in the Voždovac municipality was $39.7 \%$. The prevalence of bullying victimization observed in our study is comparable to that in Germany (29.9\%) (29) and Australia (43.3\%) (30). The prevalence of bullying in primary schools markedly varies. Relatively low prevalence of bullying victimization of $17.2 \%$ was observed in Mexico (31), while peer victimization may be as high as $91.2 \%$, as reported in the United States (32). The prevalence of bullying depends on the measurement instrument as well as on the definition and interpretation of bullying. For this reason, a comparison of bullying prevalence between different populations worldwide could be difficult.

Consistent with previous data in literature (33, 34), the majority of pupils in our sample reported having experienced some type of verbal violence. For example, in Bosnia and Herzegovina, Cerni Obrdalj et al. (34) reported that $59 \%$ of pupils experienced verbal aggression. The frequency of verbal aggression was higher compared to physical aggression. Some researchers found that bullies could be exclusively verbal/social, as opposed to all-types bullies (35). It is suggested that the peak of verbal bullying occurs between grades 6 and 8 (35). A large study of verbal bullying among more than 50,000 Brazilian adolescents reported that factors associated with being a verbal perpetrator were being male and younger, not living with both parents, witnessing family violence and having body mass index outside the healthy weight range (36). Health consequences of verbal bullying have been associated with poorer oral health (37) and sleep bruxism (38).

In this study, bullying victimization was significantly more frequent among boys and pupils in lower grades, which is in line with the findings of other authors $(31,36)$. Some authors suggested that the gender difference in bullying is related to gender roles, where boys are more aggressive per se and violence among them is reinforced (39). It is also underscored that this phenomenon enables particular individuals to become more prominent within their class or peer group (39). We observed that the prevalence of bullying victimization decreased with more advanced school grade. This could be explained by the adjustment to school environment and higher level of socialization in more advanced school grades. Paul et al. (40) suggested that the dynamics of bullying varies between classes, and that the victim is rarely only one particular pupil.

Wolke et al. (29) reported that the location of bullying is of paramount importance in a school 
setting. While in the study of Wolke et al. (29) among English and German pupils bullying most commonly occurred in the school yard, in our study classroom was the most frequent location of bullying. In addition, almost one third of pupils did not ask for help from their teachers. This could potentially be explained by the notion that some pupils do not have the confidence in their teachers and might not feel sufficiently protected. Because we found that bullying occurred, by and large, inside the classrooms, the role of the teachers is essential, as well as support from the peers (41). Jenkins et al. (41) have highlighted that social support network appears to be a crucial feature of resilience among victims to bullying. Social support includes not only the teachers and peers, but also the parents (42).

A previous study highlighted the importance of positive school climate in the promotion of antibullying behavior (43). Positive school climate has been associated with better school behaviors as well as stronger cognitive and emotional engagement of pupils in all the grades (43). These findings suggest that both general school environment and individuals (e.g. teachers and peers) have a role in prevention of bullying. In the present study, we observed that one of the most common types of bullying was calling out someone's physical appearance and origin. These results suggest that prejudice and discrimination of persons who are 'different than average' are common. We also found reports of physical bullying in schools, suggesting that there is a high level of aggression among the pupils. Bearing these findings in mind, we propose the following:

- Teachers have a key role in fostering inclusion as well as safe and supportive environment for all pupils. For this reason, teachers need to actively respond to verbal and physical bullying at the time when it occurs, as well as to promote tolerance through organized common activities where pupils are required to collaborate and share experiences as a group (44). This could be achieved inside and outside the classroom and can involve third parties that are interested and willing to participate and offer opportunities for engaging in various challenges. Cooperative learning among school peers in middle school has been deemed as a sustainable strategy to improve the interactions with schoolmates and build a school-community that will enhance the feelings of commitment and belonging and subsequently prevent school bullying (45).

- Schools should also openly address and advocate the policy of non-prejudice and nondiscrimination, by allocating the time and space to discuss differences and provide the opportunities for pupils to get personally acquainted with persons of different ethnic and cultural background or health practice. In the efforts to reduce or prevent school bullying, collaboration between the education sector and different partners has been acknowledged as a success factor (46).

\section{Limitations of the Study}

Our study sample was relatively small. Although we included only one municipality, Voždovac includes urban and suburban areas. For this reason, our results could be generalized to other urban municipalities within the city. We have not included schools from rural areas, where bullying patterns could have been different. For this reason, we cannot generalize our results to the entire country. Bullying victimization was self-reported, which is open to information bias. Thus, a false negative (missed finding referring to the pupils who did not acknowledge the existing bullying) cannot be excluded. We have not examined the intensity of bullying and the experiences of bullying from a perspective of a perpetrator. Inclusion of the bullying perpetration patterns could have provided a more nuanced information about the characteristics of primary school pupils as victims, victim-bullies and bullies. The questionnaire did not include information on social status, which may have been an important aspect concerning bullying victimization. We did not include the measures of mental health to examine potential associations between bullying victimization and character- 
istics of mental health and psychological profiles of the perpetrators and the victims.

\section{Conclusion}

This study provided an estimate of bullying victimization prevalence in primary schools of the municipality of Voždovac, Belgrade, Serbia. The prevalence of bullying victimization was rather high. Bullying victimization most often occurred within the school premises. Our findings highlight the need to establish bullying prevention strategies in primary schools. These strategies should aim at building competence among teachers for prompt recognition and response to bullying. The bullying prevention strategies should also include the parents and the community as a whole.

Acknowledgement: This study was supported by the Ministry of Science and Technological Development of the Republic of Serbia (Grant No. 175087).

Authors' Contributions: Conception and design: DKT, MS, TP; Acquisition, analysis and interpretation of data: DKT, TG, MS, VK; Drafting the article: DKT, TG, MS; Revising it critically for important intellectual content: VK, TP; Approved final version of the manuscript: DKT, TG, MS, VK, TP.

Conflict of Interest: The authors declare that they have no conflict of interest.

\section{References}

1. Hong JS, Espelage DL. A review of research on bullying and peer victimization in school: An ecological system analysis. Aggression and Violent Behavior. 2012;17(4):311-22.

2. Hager AD, Leadbeater BJ. The Longitudinal Effects of Peer Victimization on Physical Health From Adolescence to Young Adulthood. J Adolesc Health. 2016;58(3):330-6.

3. Juvonen J, Graham S. Bullying in schools: the power of bullies and the plight of victims. Annu Rev Psychol. 2014;65:159-85.

4. Casement MD, Guyer AE, Hipwell AE, McAloon RL, Hoffmann AM, Keenan KE et al. Girls' challenging social experiences in early adolescence predict neural response to rewards and depressive symptoms. Dev Cogn Neurosci. 2014;8:18-27.

5. Popadic D. Violence in schools. 2009 [cited 2020 Feb 5]. Available from http://www.mpn.gov.rs/wp-content/ uploads/2015/08/nasilje-u-skolama-za-web.pdf?fbclid=Iw
AR3ElzNWsx9CTzbZXk7lhuIEGBwpNhO8LldIYbG_ Rnzka8L5SmrXFq6WsiE

6. Shetgiri R. Bullying and victimization among children. Adv Pediatr. 2013;60(1):33-51.

7. Bilic V. Violence among peers in the real and virtual world. Paediatrics Today 2013;9(1):78-90.

8. Olweus D. School bullying: development and some important challenges. Annu Rev Clin Psychol. 2013;9:751-80.

9. Sesar K, Simic N, Sesar D. The association between bullying behavior, arousal level, coping strategies and psychological adjustment. Paediatrics Today 2013;9(1):112-28.

10. Krusell MK, Hohwü L, Bjereld Y, Madsen KB, Obel C. The impact of childhood bullying on the daily lives of Nordic children and young adolescents. Acta Paediatr. 2019;108(6):1096-102.

11. Muetzel RL, Mulder RH, Lamballais S, Cortes Hidalgo AP, Jansen P, Güroğlu B et al. Frequent Bullying Involvement and Brain Morphology in Children. Front Psychiatry. 2019;10:696.

12. Ossa FC, Pietrowsky R, Bering R, Kaess M. Symptoms of posttraumatic stress disorder among targets of school bullying. Child Adolesc Psychiatry Ment Health. 2019;13:43.

13. Wolke D, Lereya ST. Long-term effects of bullying. Arch Dis Child. 2015;100(9):879-85.

14. Koyanagi A, Oh H, Carvalho AF, Smith L, Haro JM, Vancampfort D et al. Bullying Victimization and Suicide Attempt Among Adolescents Aged 12-15 Years From 48 Countries. J Am Acad Child Adolesc Psychiatry. 2019;58(9):907-918.e4.

15. Jansen PW, Verlinden M, Dommisse-van Berkel A, Mieloo C, van der Ende J, Veenstra R et al. Prevalence of bullying and victimization among children in early elementary school: do family and school neighbourhood socioeconomic status matter? BMC Public Health. 2012;12:494.

16. Morales DX, Prieto N, Grineski SE, Collins TW. Race/ Ethnicity, Obesity, and the Risk of Being Verbally Bullied: a National Multilevel Study. J Racial Ethn Health Disparities. 2019;6(2):245-53.

17. Caravita SCS, Strohmeier D, Salmivalli C, Di Blasio P. Bullying immigrant versus non-immigrant peers: Moral disengagement and participant roles. J Sch Psychol. 2019;75:119-33.

18. Merrill RM, Hanson CL. Risk and protective factors associated with being bullied on school property compared with cyberbullied. BMC Public Health. 201616:145.

19. Jansen DE, Veenstra R, Ormel J, Verhulst FC, Reijneveld SA. Early risk factors for being a bully, victim, or bully/ victim in late elementary and early secondary education. The longitudinal TRAILS study. BMC Public Health. 2011;11:440. 
20. Semenza DC. Gender Differences in the Victim-Offender Relationship for On-and Offline Youth Violence. J Interpers Violence, in press. DOI: 10.1177/0886260519864358

21. Due P, Holstein BE, Lynch J, Diderichsen F, Gabhain SN, Scheidt P. Bullying and symptoms among school-aged children: international comparative cross sectional study in 28 countries. Eur J Public Health. 2005;15(2):128-32.

22. Belgrade. City municipalities. 2019 [cited 2019 Nov 29]. Available from http://www.beograd.rs/lat/gradskavlast/1904-gradske-opstine/

23. Statistical Office of the Republic of Serbia. 2011 Census of Population, Households and Dwellings in the Republic of Serbia. Population. Age and sex. Data by dwellings. 2012 [cited 2020 Nov 29]. Available from https://publikacije. stat.gov.rs/G2012/Pdf/G20124002.pdf

24. City municipality Voždovac. Education and science. Primary schools of municipality of Voždovac. 2019 [cited 2020 Nov 30]. Available from https://vozdovac.rs/obrazovanje-i-nauka/\#1448458151514-26110a44-0bb1

25. Raosoft.com. Database web survey software for gathering information, 2004 by Raosoft, Inc. [updated 2008 January 21; cited 2019 Nov 30]. Available from: http://www. raosoft.com/samplesize.html.

26. Mynard H, Joseph S. Development of the Multidimensional Peer-Victimization Scale. Aggress Behav. 2000;26:169-78.

27. Solberg ME, Olweus D. Prevalence estimation of school bullying with the Olweus Bully/Victim Questionnaire. Aggress Behav. 2003;29:239-68.

28. Greif JL, Furlong MJ. The assessment of school bullying: Using theory to inform practice. J Sch Violence. 2006;5(3):33-50.

29. Wolke D, Woods S, Stanford K, Schulz H. Bullying and victimization of primary school children in England and Germany: prevalence and school factors. Br J Psychol. 2001;92(Pt 4):673-96.

30. Bond L, Carlin JB, Thomas L, Rubin K, Patton G. Does bullying cause emotional problems? A prospective study of young teenagers. BMJ. 2001;323(7311):480-4.

31. Hidalgo-Rasmussen CA, Ramírez-López G, Rajmil L, Skalicky A, Martín AH. Bullying and health-related quality of life in children and adolescent Mexican students. Cien Saude Colet. 2018;23(7):2433-41.

32. Russo JN, Griese ER, Bares VJ. Examining the Prevalence and Impact of Peer Victimization and Social Support for Rural Youth. S D Med. 2018;71(10):448-51.

33. Seals D, Young J. Bullying and victimization: prevalence and relationship to gender, grade level, ethnicity, self-esteem, and depression. Adolescence. 2003;38(152):735-47.
34. Cerni Obrdalj E, Rumboldt M. Bullying among school children in postwar Bosnia and Herzegovina: cross-sectional study. Croat Med J. 2008;49(4):528-35.

35. Wang J, Iannotti RJ, Luk JW. Patterns of adolescent bullying behaviors: physical, verbal, exclusion, rumor, and cyber. J Sch Psychol. 2012;50(4):521-34.

36. Azeredo CM, Levy RB Araya R, Menezes PR. Individual and contextual factors associated with verbal bullying among Brazilian adolescents. BMC Pediatr. 2015;15:49.

37. Barasuol JC, Soares JP, Castro RG, Giacomin A, Gonçalves BM, Klein D et al. Untreated Dental Caries Is Associated with Reports of Verbal Bullying in Children 8-10 Years Old. Caries Res. 2017;51(5):482-8.

38. Serra-Negra JM, Pordeus IA, Corrêa-Faria P, Fulgêncio LB, Paiva SM, Manfredini D. Is there an association between verbal school bullying and possible sleep bruxism in adolescents? J Oral Rehabil. 2017;44(5):347-353.

39. Carrera Fernández MV, Fernández ML, Castro YR, Failde Garrido JM, Otero MC. Bullying in Spanish secondary schools: gender-based differences. Span J Psychol. 2013;16:E21.

40. Paul S, Smith PK, Blumberg HH. Surveying bullying using peer nomination methods. Paediatrics Today 2013;9(1):102-11.

41. Jenkins LN, Fredrick SS, Wenger J. Peer victimization and social-emotional outcomes: The role of teacher and peer support. Aggress Behav. 2018;44(2):176-84.

42. van Niejenhuis C, Huitsing G, Veenstra R. Working with parents to counteract bullying: A randomized controlled trial of an intervention to improve parent-school cooperation. Scand J Psychol, in press. DOI 10.1111/sjop.12522.

43. Yang C, Sharkey JD, Reed LA, Chen C, Dowdy E. Bullying victimization and student engagement in elementary, middle, and high schools: Moderating role of school climate. Sch Psychol Q. 2018;33(1):54-64.

44. Dobia DC, Carney JS. Creating a Culture of Tolerance in Schools. J Sch Violence. 2002; 1(2):87-103.

45. Van Ryzin MJ, Roseth CJ. Cooperative Learning in Middle School: A Means to Improve Peer Relations and Reduce Victimization, Bullying, and Related Outcomes. J Educ Psychol. 2018;110(8):1192-201.

46. United Nations Educational, Scientific and Cultural Organization (UNESCO). 2019. Behind the numbers: Ending school violence and bullying. [cited 2020 Feb 5]. Available from https://reliefweb.int/sites/reliefweb.int/files/ resources/366483eng.pdf 